\title{
Fluctuation of sea surface temperature in the Persian Gulf and its impact on coral reef communities around Kish Island
}

\begin{abstract}
Sea Surface Temperature (SST) is a critical parameter which can affect the health of coral reef communities. The Persian Gulf consists of various types of coral reefs, especially around the islands such as Kish Island. NOAA-Pathfinder-5 provides a valuable global dataset including the SST values of the water bodies. This research focuses on the studies of fluctuations SST values of near-shore waters around the Kish Island during 1985 to 2009 using NOAA-Pathfinder-5 dataset and field observed data including direct underwater photography and photo-transecting by snorkeling. Subsequently, the results were analyzed to study the impacts of these fluctuations on main coral reef communities such as Acroporids and Faviids in the studied area. Statistical analyses on SST data showed a meaningful and positive correlation between the SST values and bleaching in coral reefs. Specifically, in August 1998 and 2007, this phenomenon was clearly observable when most of corals have been affected by the bleaching phenomenon when the SST values were $\sim 1.5^{\circ} \mathrm{C}$ higher than normal situation. Coral reefs showed their ability to recover themselves after the anomalous dates, if the SST values remained normal enough for a long period of time.
\end{abstract}

Keyword: Sea surface temperature (SST); Remote sensing; NOAA-Pathfinder-5; Coral reef; Bleaching; Kish Island 